\title{
Study of Implementation of Society Management System
}

\author{
Shivganga Gavhane \\ Asst. Prof Computer Engineering,DYPIEMR
}

\author{
Swati Sonar \\ Computer Engineering,SPPU
}

\author{
Rutuja Vatharkar \\ Computer Engineering,SPPU \\ Pratiksha Patil \\ Computer Engineering,SPPU
}

\begin{abstract}
This paper discusses about the study of implementation of Android Application for housing society management. Daily life in city areas has important things to deal with housing society management. Our day to day needs such as Water supply, Electricity, Security and many more things which directly or indirectly plays vital role in residential life, comes under Housing Society Management. In most of the cases, Society management practices a traditional way of communication. This certainly has some limitations and disadvantages.
\end{abstract}

Daily notices, monthly meetings, cultural events, miscellaneous contacts for daily needs, security alerts, high priority communication and many others which may not be conveyed properly in current scenario as most of the things are getting handled manually. It lacks transparency. To overcome the problems occurring due to this time lagging manual system, an automated system needs to be developed.

\section{Keywords}

Android, Messaging, Notification, Cloud Computing, MVC architecture, Database, Push notification services.

\section{INTRODUCTION}

Now a days, Android is most popular platform in smart mobile communication. In Indian economy, Android is a very affordable technology which every other citizen can buy. Since mobile devices have become more and more powerful and distributive, mobile computing has significantly changed our everyday life. As smart phones are widely used by everyone now-a-days it provides an effective platform for communication via an android application.

As Android is open source and having flexible and customizable user interface, thus one of the most popular mobile operating system...indeed a revolutionary. This project mainly uses "Push Notification Technology" through android platform.

The application mainly featured with fruitful solution for Day to day notifications for meetings, water management, electricity management, parking, miscellaneous contacts, security alerts and high priority communication. It will definitely reduce the human efforts and errors to increase crystal clear transparency between society members and management.

It will be very much reliable way of communication irrespective of time and location. One can remain connected with society members around the clock. In addition to that it will save time, paper work, and human efforts and offers reliability.

\section{LITERATURE SURVEY}

This is a study of research paper for Multipurpose Android Based Mobile Notifier, Google cloud messaging, Android application related to notification system.

The idea behind these papers is to study various methods and techniques to push notification on various android devices. It follows principle of cloud computing and distributed computing. There are many handful technologies, which push data or content on mobile devices/tablets. The need of technologies studied are Google Cloud Messaging (GCM), C2DM (Cloud to Device Messaging) and Xtify is for authenticating a user, as well as handling all aspects of messages and delivery to the target application on the target device. The basic notification application is implemented using Google Cloud messaging.[4]

Google Cloud Messaging for Android (GCM) provides a facility to send data from server to Android mobile device of user, and also receives messages from other devices within a network according to Android developer website, "a service that helps developers sends data from servers to their Android applications on Android devices." Hence, the overall purpose and scope of this project is reachable by Push notification technology (GCM)[9].

\section{EXISTING SYSTEM}

In current situations, housing society management authorities use a traditional way of communication which include a common notice board system operated by responsible society member. Many of societies also have started using automated chat systems which are definitely useful up to certain extent but though fails to serve purpose. Here are some basic disadvantages of these methods:

\subsection{Notice Board System}

\subsubsection{Unreachable information:}

Notice board is a system which is one to many kind of system having a notifier and Society members involved. Many of times it happens that an admin or notifier fails to update the notice board or society members ignore to follow the notice board. It results in lack of communication.

\subsubsection{Lack of authenticity and reliability:}

Notice board can be operated manually it might be handwritten or printed format. In general practice it can be easily altered or misplaced and may lead to wrong interpretation. Also it can be affected with any unauthentic data as well.

\subsubsection{Time consuming activity:}

One has to take whole responsibility to operate and maintain the notice board. It creates dependability with specific person. Sometimes the person has to compromise with his own time schedule for these common activities. 


\subsubsection{Missing of acknowledgement:}

As this is manual system one cannot predict, whether the notice is reached out to every concern person. And any kind of acknowledgment is missing also it creates overhead to reschedule or inform any kind of change.

\subsection{Automated chat system}

This kind of systems are useful as a common chat window but fails to provide specific environment for dedicated purpose which results in unnecessary information sharing dominating the main content.

\section{PROPOSED SYSTEM}

To overcome the drawbacks of existing system, this paper is proposing a smarter way of communication. As discussed earlier an automated notification system can be developed using a very popular Android platform which will provide a user friendly mobile based application which can be beneficial on following fronts:

\subsection{Multiple Reminders}

The application can provide gentle reminders through automated system till the actual event execution. It will reduce human efforts for member to member follow up. Once the event is created by admin, rest of the things will be taken care by application itself. It will definitely reduce the chances of errors and miscommunication.

\subsection{Authentic and uninterrupted communication with management}

In this particular regard, it often seems that complaints by society members remain unattended by higher management and member has to suffer. One has to take continuous follow up till the issue get resolved. The application can provide an assurance to follow up every complaint made by society member. Basically user can raise a complaint from any location irrespective of personal availability of concern person.

\subsection{Time saver and Go Green activity}

As this is a mobile based communication platform. Admin can push notices, create events, ask for complaints and many more things within a minute. It will bypass a long process of making a well structured, presentable form of any kind of notice.

Besides being paperless activity, this will be a small helping hand for Go Green activity which will avoid use of ecodestructive products.

\subsection{Society Relevant User Experience}

Being a business product this can propose a customizable, more user friendly, and tailor made kind of application. It will provide more relevant user experience with specific Meta data related to particular society.

In short this application can be a very reliable and disciplined way of communication to keep a healthy bonding in between society members and management.

\section{IMPLEMENTATION}

As application is based on mobile platform it uses MVC (Model-View-Controller) architecture as seen in fig $1 .$. In MVC view is a user interface part through which user can interact with the system and is a output representation of information. Model captures the behavior of the application in terms of its problem domain, independent of the user interface [5]. It includes all that which will be displayed on the interface. Controller accepts the input and converts it to the commands for model or view. It includes the business logic for the application.

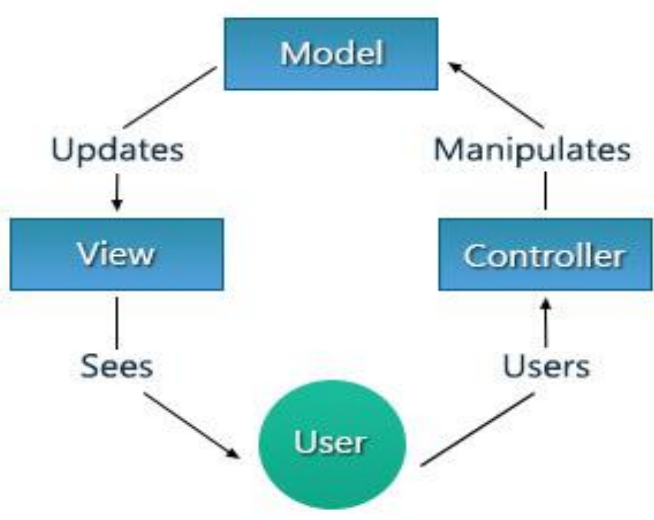

Figure 1 MVC Architecture (courtesy [5])

Thus the Application can have three components as Android application, Business logic and database.

\subsection{Android application}

It is an application developed in Eclipse using android programming. Through which user can register interact and access the services provided by application as shown in Fig.2 and Fig.3. Android application have 4 major pillars which are Activities, Services, Content provider and Broadcast receiver. Activity is the User Interface through which user can interact with the application. Fig.2 and Fig.3 shows sample activities which can be included in application.

\subsection{Business logic}

It acts as a bridge between application, database and make access to database possible.

\subsection{Database}

Data of user is stored in database at the time of registration and later can be fetched or modified. Thus Push Notification technology is applied as "logic" to fetch the data from "database" and represent using "view" for various operations offered by an application.

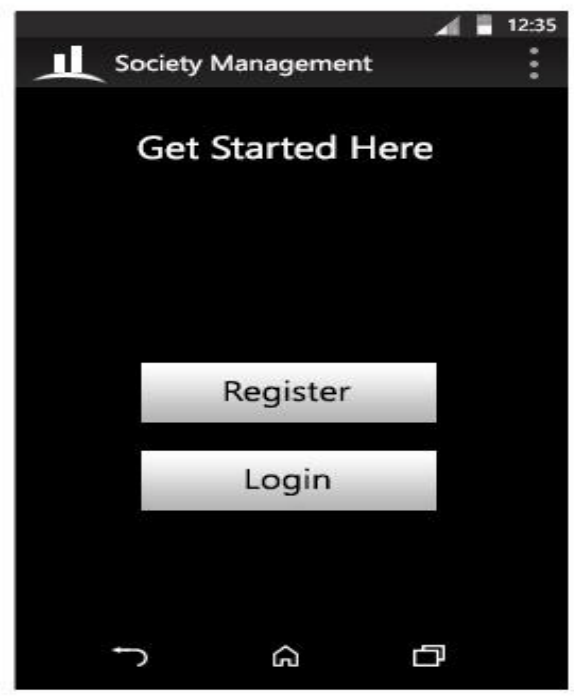

Figure 2 Activity 1 (Courtesy [5]) 


\section{ADVANTAGES}

This application will notify people for events and activities in the society personally so that people can actively participate in those activities and thus increases interaction with neighbors.

1. Notifications will be pushed so as to remind user before time.

2. Reduces efforts and time for conveying messages manually.

3. Reliable and transparent.

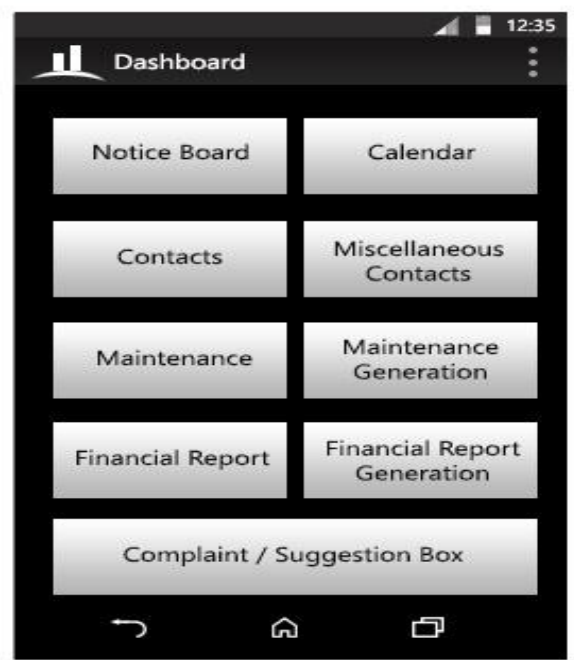

Figure 3 Activity 2 (Courtesy [5])

\section{APPLICATIONS}

1. It can be used in residential societies where apartments are ranging from small to big in numbers.

2. To convey notices or other information among others which is necessary but not feasible using primary resources such as notice boards or phone calls.

\section{CHALLENGES}

To get a domain knowledge by visiting various housing comnlexes and to understand their day to day requirements : IJCATM : www.ijcaonline.org ociety's strength varies from wnships. Accordingly the requirements of client can be modified and customizing of the product within a short period may be a challenge. Multiple reminders can be interruptible for user though it is necessary. But it varies from man to man psychology.

\section{CONCLUSION}

The entire solution will provide a hassle free, user friendly affordable communication platform to develop healthy relations between hosing society members and a smarter way of interconnectivity. Application manages housing society through "Push Notification Technology" that will assist the society members to play their roles effectively.

Chairman or secretary will play the role of administrator allowing registration of residents so that they can use these registration details to login and to access the services. This project may use concepts of data mining and artificial intelligence And economical management for future work.

\section{ACKNOWLEDGEMENT}

It gives us immense pleasure to present the preliminary study paper for project on "Society management system". Any project consumes lot of research work and dedication. A study would not have been possible if we did not have a support of many individuals and organizations. We would like to extend our sincere gratitude to all of them.

We are thankful to our internal guide, HOD, Principal, Friends and Family for provision of expertise and technical support.

\section{REFERENCES}

[1] BinPeng Jinming Yue,Chen Tianzhou, "TheAndroidApplicationDevelopmentCollegeChallenge "IEEE,2012,pp-1677-1681

[2] http://www.tutorialspoint.com/struts_2/basic_mvc_archit ecture.htm

[3] http://www.tutorialspoint.com/sdlc/sdlc_waterfall_model .htm

[4] Jarle Hansen, Tor-Morten Grønli, Gheorghita Ghinea," Cloud to Device Push Messaging on Android: a Case Study”,ICAINA,2012,pp-1298-1303

[5] Omkar Singh1, Aditee Lakhan2, Jyoti Gupta3, "Implementation of an Android Application for Management of aHousing Society",IJECS,2015, vol4,pp-12383-12389

[6] Saurabh Malgaonkar, Vivek Maurya, Mukul Kulkarni, Gurtej Singh Majithia, "Multipurpose Android Based Mobile Notifier”, ICAECC,2014,pp-1-4

[7] Seth Y.Fiawoo and Robert A. Sowah, "Design and Development of an Android Application to Process and Summarize Corporate Data",IEEE,2012,pp-1-6

[8] SHAO Guo-hong, "Application Development Research Based on Android Platform",ICICTA,2014,pp-579-582

[9] Yavuz Selim Yilmaz, Bahadir Ismail Aydin, Murat Demirbas, "Google Cloud Messaging (GCM): An Evaluation" IEEE,2014, pp-2807-2812 